\title{
Supplemental macronutrients and microbial fermentation products improve the uptake and transport of foliar applied zinc in sunflower (Helianthus annuus L.) plants. Studies utilizing micro X-ray florescence
}

\section{Shengke Tian 1,2, Lingli Lu' ${ }^{1}$, Ruohan Xie ${ }^{1,2}$, Minzhe Zhang ${ }^{2}$, Judith A. Jernstedt ${ }^{2}$, Dandi Hou' Cliff Ramsier $^{3}$ and Patrick H. Brown ${ }^{2 *}$}

MOE Key Laboratory of Environment Remediation and Ecological Health, College of Environmental and Resource Science, Zhejiang University, Hangzhou, China

2 Department of Plant Sciences, University of California, Davis, Davis, CA, USA

${ }^{3}$ Ag Spectrum Company, Vero Beach, FL, USA

Edited by:

Ebrahim Hadavi, Islamic Azad

University, Iran

Reviewed by:

Victoria Fernandez, Technical University of Madrid, Spain José López-Bucio, Universidad Michoacana de San Nicolás de Hidalgo, Mexico

${ }^{*}$ Correspondence:

Patrick H. Brown, Department of Plant Sciences, University of California, Davis, One Shields Avenue, Davis, CA 95616, USA

e-mail:phbrown@ucdavis.edu
Enhancing nutrient uptake and the subsequent elemental transport from the sites of application to sites of utilization is of great importance to the science and practical field application of foliar fertilizers. The aim of this study was to investigate the mobility of various foliar applied zinc (Zn) formulations in sunflower (Helianthus annuus L.) and to evaluate the effects of the addition of an organic biostimulant on phloem loading and elemental mobility. This was achieved by application of foliar formulations to the blade of sunflower $(H$. annuus $L$.) and high-resolution elemental imaging with micro $X$-ray fluorescence ( $\mu$-XRF) to visualize $\mathrm{Zn}$ within the vascular system of the leaf petiole. Although no significant increase of total $\mathrm{Zn}$ in petioles was determined by inductively-coupled plasma mass-spectrometer, $\mu-X R F$ elemental imaging showed a clear enrichment of $\mathrm{Zn}$ in the vascular tissues within the sunflower petioles treated with foliar fertilizers containing $\mathrm{Zn}$. The concentration of $\mathrm{Zn}$ in the vascular of sunflower petioles was increased when $\mathrm{Zn}$ was applied with other microelements with EDTA (commercial product Kick-Off) as compared with an equimolar concentration of $\mathrm{ZnSO}_{4}$ alone. The addition of macronutrients N, P, K (commercial product CleanStart) to the Kick-Off Zn fertilizer, further increased vascular system Zn concentrations while the addition of the microbially derived organic biostimulant "GroZyme" resulted in a remarkable enhancement of $\mathrm{Zn}$ concentrations in the petiole vascular system. The study provides direct visualized evidence for phloem transport of foliar applied $\mathrm{Zn}$ out of sites of application in plants by using $\mu$-XRF technique, and suggests that the formulation of the foliar applied Zn and the addition of the organic biostimulant GroZyme increases the mobility of $\mathrm{Zn}$ following its absorption by the leaf of sunflower.

Keywords: foliar fertilizer, remobilization, sunflower, $\mu$-XRF, zinc, microbial fermentation, biostimulant

\section{INTRODUCTION}

Sunflower (Helianthus annuus L.) is an oilseed crop of great importance worldwide, due to the excellent quality of the oil extracted from its seeds that are consumed in various ways. Cultivation of the sunflower is becoming increasingly significant globally (Coelho Bezerra et al., 2014). In 2008-2009, the world sunflower seed production was about 33 million tones, around $8.5 \%$ of the world's total oilseed production (http://www.agricommodityprices.com), the leading producers of which are the EU, Russia, Ukraine, Argentina, USA, China, India, and Turkey (Lomascolo et al., 2012).

Foliar fertilization is an increasingly popular practice with particular importance for the production of high value crops (Fernández and Brown, 2013; Fernández etal., 2013) such as sunflowers with many examples of positive responses to foliar application of micronutrients, including zinc $(\mathrm{Zn})$, iron $(\mathrm{Fe})$,

Abbreviations: $\mu$-XRF, micro X-ray fluorescence. boron (B), manganese (Mn), and molybdenum (Mo), on the seed yield and seed quality of sunflower (Jabeen et al., 2013; Skarpa, 2013; Skarpa et al., 2013; Tohidi-Moghadam, 2013; Yang et al., 2013; Tahir et al., 2014). Foliar fertilization has particular value in overcoming nutrient deficit resulting from stress conditions, such as salinity and drought, which often compromise root growth and decrease root absorption capacity (Kannan, 2010). Foliar application of $\mathrm{Zn}$ resulted in a greater improvement in $\mathrm{Zn}$ densities in rice and wheat grain when compared with soil applied $\mathrm{Zn}$ (Ebrahimian et al., 2010; Phattarakul et al., 2012; Zhang et al., 2012).

Foliar fertilization is theoretically more immediate and targetoriented than soil fertilization since nutrients can be directly delivered to plant tissues during critical stages of plant growth (Fernández and Brown, 2013; Fernández et al., 2013). Optimizing the efficacy of the foliar applied nutrients is therefore of great importance from an economic, agronomic and environmental point of view. Our understanding of the factors that determine 
the ultimate efficacy of foliar applications remains poor and the response of plants to foliar $\mathrm{Zn}$ applications is highly variable (Fernández and Brown, 2013). Many reports indicate that foliar application of $\mathrm{Zn}$ may significantly increase the concentrations of $\mathrm{Zn}$ in the applied leaves but may have little effect on foliar concentrations in non-sprayed tissues or tissue that develop subsequent to the foliar application (Zhang and Brown, 1999; Mirzapour and Khoshgoftar, 2006; Sanchez et al., 2006). The factors that control the uptake and subsequent translocation of foliar applied nutrients out of the leaf, and the effect of spray formulation on these processes are poorly understood (Bukovac, 1985; Adamec, 2013; Fernández and Brown, 2013). While various approaches have been used to determine the efficacy of foliar applied nutrients using stable and radioactive isotopic labeling (Wittwer and Teubner, 1959; Bukovac, 1985; Sah and Brown, 1998; Boaretto et al., 2001; Sanchez et al., 2006), it remains challenging to determine the pathways of mobilization from leaf to shoot and to monitor the influence of foliar formulation on phloem loading and micronutrient transport.

To address the inherently low efficiency of many foliar $\mathrm{Zn}$ formulations, a wide range of commercial products have been developed and marketed (Fernández et al., 2013). Recently, there has been much interest in the incorporation of organic molecules (sugars, amino acids, polysaccharides etc.) or biostimulants into foliar fertilizers with the rationalization that these additives will enhance the uptake, or subsequent mobility of the applied nutrient (Fernández et al., 2013). The term 'biostimulant' is used to describe a substance or material, with the exception of nutrients and pesticides, which when applied to plants has the capacity to beneficially modify plant growth (Calvo et al., 2014). Currently there is very little scientific evidence that biostimulants can specifically enhance the uptake and utilization of foliar applied fertilizer materials.

The technique of X-ray fluorescence (XRF) has been widely used in the research of elemental distribution in plant tissues, and has proved to be a promising tool to study in vivo localization of metals in plants due to its high-resolution and sensitivity (Punshon et al., 2009; Zhao et al., 2014). XRF analyses can be performed to visualize cellular and subcellular distribution of elements in plants without significant pretreatment of the samples. We have previously applied this technique to characterize the location and to monitor changes in concentration and distribution of $\mathrm{Zn}$ during plant development or following foliar applications ( $\mathrm{Lu}$ et al., 2013a,b; Tian et al., 2014). In this current study, we will utilize $\mu$ XRF to obtain high spatial quantification (cellular and subcellular) of elemental distribution and transport following the application of various $\mathrm{Zn}$ formulations with the aim of: (1) increasing our understanding of the processes that govern the localization and transport of foliar applied nutrients with emphasis on $\mathrm{Zn}$, and (2) to determine if the formulation of the foliar applied $\mathrm{Zn}$, with addition of macronutrients or biostimulant, alters the mobility of the element following its absorption by the leaf of sunflower.

\section{MATERIALS AND METHODS PLANT CULTURE}

Sunflower ( $H$. annuus L.) seeds were imbibed at $4^{\circ} \mathrm{C}$ for 2 days and allowed to germinate in darkness at room temperature for 3 days.
Seedlings were planted in potting soil. The pots were in $20 \mathrm{~cm}$ diameter, $20 \mathrm{~cm}$ tall, and filled with a soil mixture containing (\% of volume) $40 \%$ peat, $35 \%$ silica clay, $20 \%$ perlite, and $5 \%$ gravel. One plant per pot, and placed in a greenhouse (photo flux density of $400 \mu \mathrm{mol} \mathrm{m}{ }^{-2} \mathrm{~s}^{-1}$, light/dark period of $16 / 8 \mathrm{~h}$, day/night temperature of $25 / 20^{\circ} \mathrm{C}$ and day/night humidity of $70 / 85 \%$ ). Plants were watered as needed by irrigation (usually twice per day) with a nutrient solution of the following composition: $1.2 \mathrm{mM} \mathrm{KNO}_{3}$, $0.8 \mathrm{mM} \mathrm{Ca}\left(\mathrm{NO}_{3}\right)_{2}, 0.8 \mathrm{mM} \mathrm{NH}_{4} \mathrm{NO}_{3}, 0.3 \mathrm{mM} \mathrm{KH}_{2} \mathrm{PO}_{4}$, and $0.2 \mathrm{mM} \mathrm{MgSO}_{4}, 12 \mu \mathrm{M}$ Fe-EDTA, $0.25 \mu \mathrm{M} \mathrm{Na} \mathrm{B}_{8} \mathrm{O}_{13} \cdot 4 \mathrm{H}_{2} \mathrm{O}$,

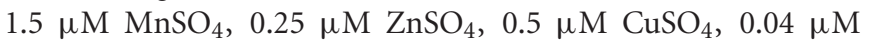
$\mathrm{Na}_{2} \mathrm{MoO}_{4}$.

\section{TREATMENTS WITH DIFFERENT FOLIAR FERTILIZERS}

After 1 month of growth, plants of sunflowers were watered with nutrient solution without $\mathrm{Zn}$ for 7 days. Fully expanded leaves of sunflowers were then washed thoroughly with deionized water, and immersed for $10 \mathrm{~s}$ in $250 \mathrm{~mL}$ solution containing different nutrients. Treatments include surfactant sprayed control, "CleanStart," "Kick-Off," "CleanStart" + "Kick-Off," "CleanStart" + "Kick-Off" + "GroZyme," and $\mathrm{ZnSO}_{4}$. All materials were applied so that final $\mathrm{Zn}$ concentrations in the applied material and volume of applied materials were equivalent. The nutrient composition of the different treatments is shown in Table 1. Because of the complex nature of the commercial products used, it was not possible to prepare a control spray treatment that contained equivalent amounts of all nutrient elements present in Kick-Off or CleanStart. At the rate used here, GroZyme contains negligible concentrations of all essential plant elements. To avoid the possibility that the effect of the foliar spray was a consequence of alleviation of secondary (not $\mathrm{Zn}$ ) nutrient deficiency, all plants were grown with continuous and abundant soil nutrient. Leaf analysis was conducted and all nutrients were found to be present at adequate levels and plants showed no sign of nutrient deficiency. The foliar fertilizer product "CleanStart," "Kick-Off," and "GroZyme" were obtained from Ag Spectrum Company (DeWitt, IA, USA). $0.1 \%$ Silwet L-77 (v/v) was added in each solution. The solutions were applied to the leaves of sunflower $8 \mathrm{~h}$ before darkness $(10 \mathrm{am})$, and all plant tissues except the sprayed leaf were covered to prevent inadvertent spray application. The petioles of all sprayed leaves were carefully protected by coating the leaf base petiole junction with lanolin (Sigma) and Teflon membranes. Four plants were treated as one replication, with three replications for each treatment. The foliar application of the fertilizers was replicated one time after 7 days, and then plants were harvested 7 days later.

GroZyme is a microbial fermentation product derived from a proprietary mix of organic cereal grains inoculated with specific bacterial cultures and fermented. The fermentation process occurs under controlled environmental conditions until a specific metabolic profile is achieved at which time the live bacterium are liaised and the material is filtered to remove large particles. This concentrate is then extended and stabilized to make the final product. Soil applications of GroZyme have been reported to alter soil microbial activity and nitrogen transformations (Chen etal., 2002, 2003). The metabolic basis for the biological activity of foliar applied GroZyme is not 
Table 1 | Elemental composition of the foliar fertilizers ( $\mathrm{mg} \mathrm{L}^{-1}$ in solution).

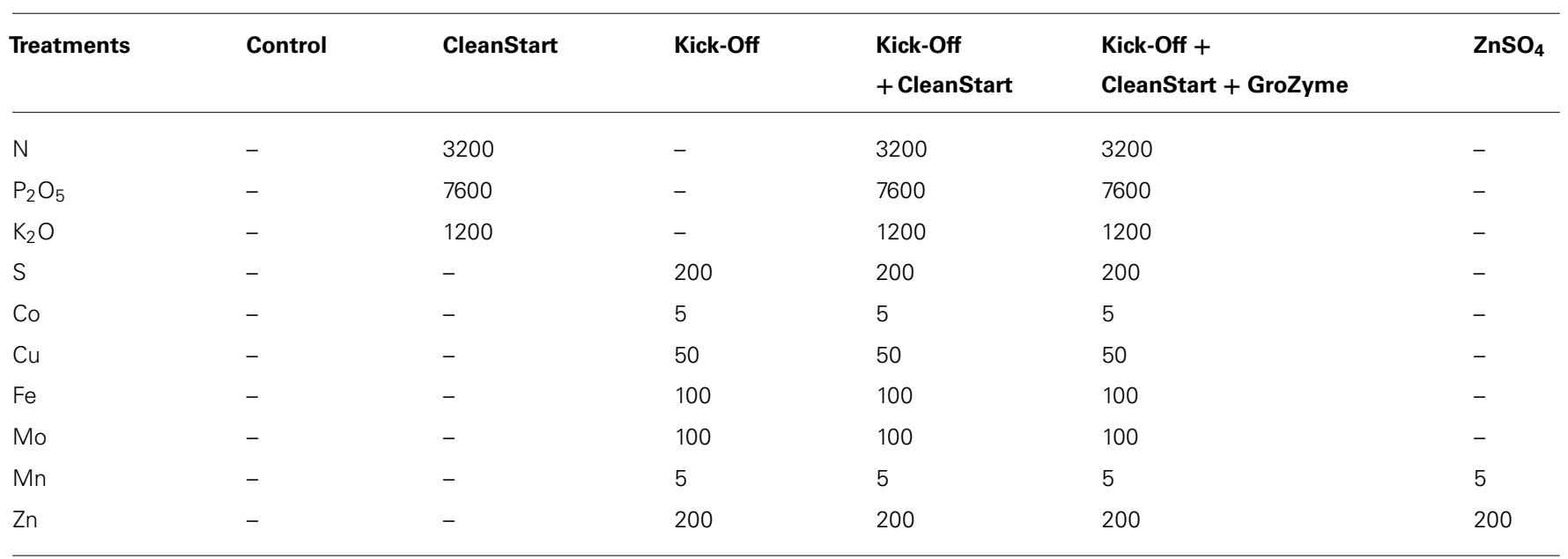

known. However, field observations suggest that GroZyme functions to enhance plant growth by enhancing $\mathrm{K}$ metabolism and sugar transport (Ag Spectrum, unpublished results). CleanStart is derived from ammonia, urea, orthophosphoric acid and potassium hydroxide, and Kick-Off is a micronutrient mix of $\mathrm{Fe}, \mathrm{Mn}, \mathrm{Cu}, \mathrm{Zn}$ predominantly derived from nitrate sources with additional surfactants and stabilizers. The elemental composition of all spray applications is provided in Table 1.

\section{ELEMENTAL ANALYSIS}

The petioles of leaves were oven-dried at $65^{\circ} \mathrm{C}$ for $72 \mathrm{~h}$, then ground using a stainless steel mill and passed through a $0.25-\mathrm{mm}$ sieve for analysis of nutrient elements. Ground, dry plant samples $(0.1 \mathrm{~g})$ of each treatment were digested with $5.0 \mathrm{~mL} \mathrm{HNO}_{3}-\mathrm{HClO}_{4}$ (v/v: 4:1), and the digest was transferred to a $50-\mathrm{mL}$ volumetric flask, made up to volume with water and filtered. Concentrations of mineral elements (i.e., $\mathrm{Zn}, \mathrm{Fe}, \mathrm{Cu}, \mathrm{Mn}, \mathrm{B}, \mathrm{K}, \mathrm{Ca}$, and $\mathrm{Mg}$ ) in the filtrates were analysed using inductively coupled plasma mass spectroscopy (ICP-MS; Agilent 7500a, USA).

\section{ELEMENTAL MAPPING BY $\mu$-XRF Sample preparation}

Mid-sections of leaf petioles were cut from the leaves treated with different foliar treatments. Leaf cross-sections (100 $\mu \mathrm{m}$ thick) were cut with a cryotome (LEICA, CM1850) at a temperature of $-20^{\circ} \mathrm{C}$ (Tian etal., 2014). Single sections of each treatment were selected under light microscopy for their ultrastructural integrity and then freeze-dried under $-20^{\circ} \mathrm{C}$ for 3 days prior to $\mu$-XRF analysis. Since $\mu$-XRF analysis is time consuming and expensive only single samples from each treatment could be analyzed. Given that true replicate analyses could not be performed additional steps were taken to avoid the potential for experimental artifacts and to avoid any sample selection or analysis bias. All treatments were carefully controlled such that treatment conditions and experimental duration were identical; petioles were then taken from the four replicate plants and multiple sections from each petiole were prepared as described above. All sections were then assessed by light microscopy for ultrastructural integrity and a single section was then selected and transported to the Stanford Synchrotron Radiation Laboratory (SSRL) for $\mu$-XRF analysis. Samples selected in this fashion, therefore represent unbiased examples of treatment effects.

\section{$\mu-X R F$ analysis}

Micro-XRF imaging was performed on the SSRL using beamlines 2-3. Experiments on SSRL beamline 2-3 were recorded at $13500 \mathrm{eV}$. The incident X-ray beam of $2 \mu \mathrm{m}$ in beamline 2-3 was focused using a pair of Kirkpatrick-Baez mirrors, and the incident beam was monochromatized using a Si (111) double-crystal monochromator. Micro-XRF maps were obtained by rastering the beam at 20 and $5 \mu \mathrm{m}$ steps, with a count time of $200 \mathrm{~ms}$ per step, for the following major and minor/trace elements: P, S, Cl, K, Ca, Mn, Fe, Cu, and Zn. Fluorescence signal intensities for the above elements were calculated in SMAK software (Webb, 2014). The fluorescence data were presented as tricolor maps that allow for the spatial distribution of three elements to be shown. Pixel brightness was displayed in RGB, with the brightest spots corresponding to the highest element fluorescence.

\section{STATISTICAL ANALYSIS OF DATA}

All data were statistically analyzed using SPSS (Version 12.0). The figures were made using the software Origin 8.0.

\section{RESULTS \\ DISTRIBUTION PATTERNS OF NUTRIENTS IN LEAF VEIN}

To investigate the effects of different fertilizers on retranslocation of nutrients in the leaves of sunflower, $\mu$-XRF mapping was performed. Cross sections of petioles were cut from the sunflower plants at approximately $1.0 \mathrm{~cm}$ below the leaves and imaged under a light microscope prior to utilization for $\mu$-XRF imaging (Figure 1). The cross section of petiole was composed of epidermis, parenchyma, vascular bundle containing xylem, phloem, and surrounding collenchyma. The microscope image in Figure 1 shows that the phloem within the vascular bundle exists as a discrete layer of cells on the abaxial (morphological bottom) side of 


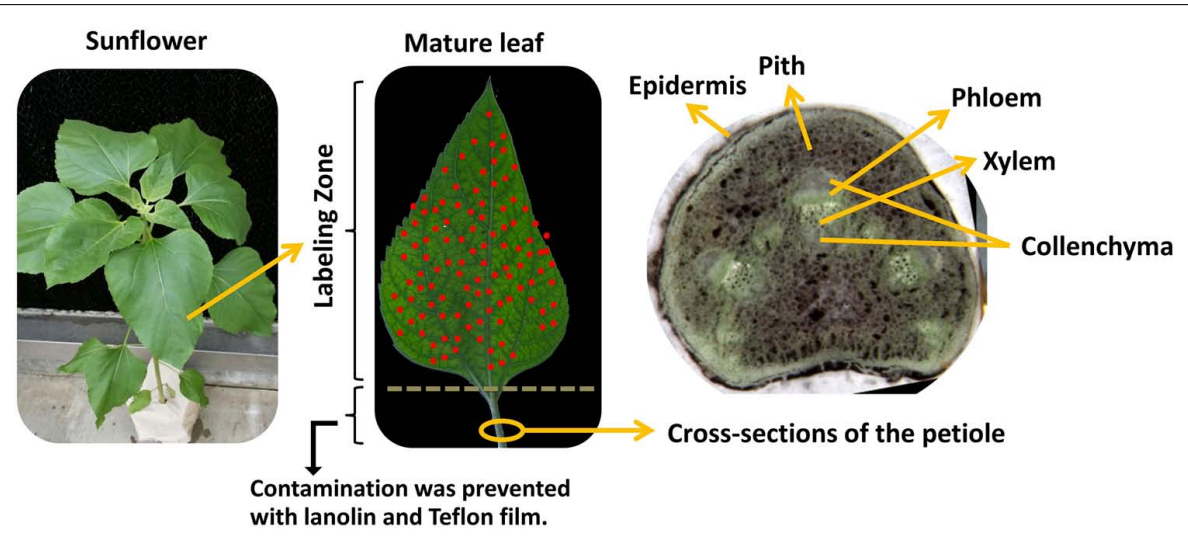

FIGURE 1 | Microscope image of petiole cross-section collected from sunflowers plants after foliar application. Fully expanded leaves of 1-month old sunflower were treated with different foliar fertilizers, then cross-sections of the petiole were cut by cryotome at $-20^{\circ} \mathrm{C} 7$ days after final foliar fertilization treatment.
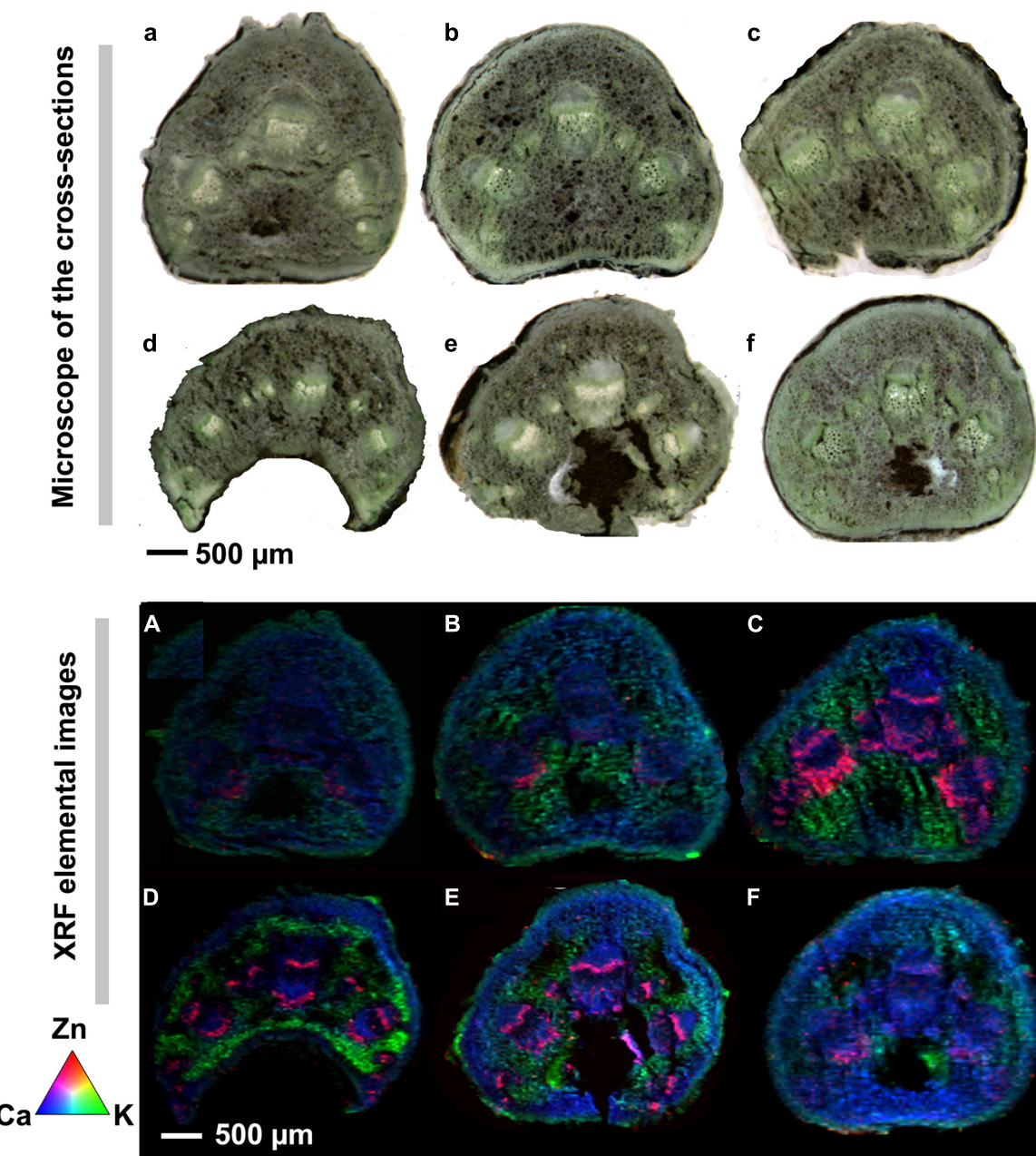

B
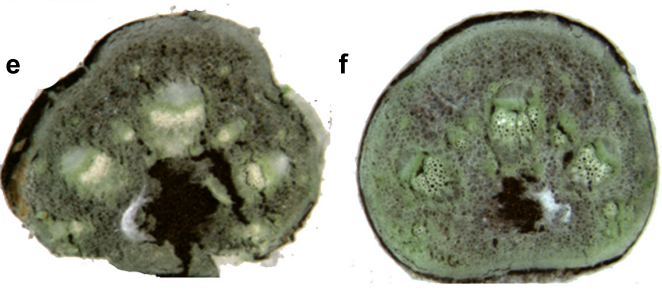

c

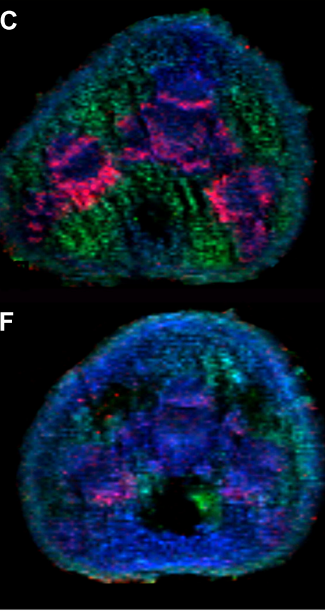

FIGURE 2 | Microscope cross sections (a-f) and $\mu$-XRF elemental maps (A-F) for Zn (red), Ca (green), and K (blue) of petioles collected from sunflowers subject to different foliar fertilizers. Cross-sections of leaf veins were cut from sunflower plants treated with $(\mathbf{a}, \mathbf{A})$ control, $(\mathbf{b}, \mathbf{B})$ CleanStart, (c, C) Kick-Off, (d, D) CleanStart + Kick-Off, (e, E)
CleanStart + Kick-Off + GroZyme, and (f, F) $\mathrm{ZnSO}_{4}$, and then analyzed by $\mu-X R F$ imaging. Compositions of the nutrients in different treatments are shown in Table 1. Pixel brightness for $\mu-X R F$ map (A-F) is displayed in RGB, with the brightest spots corresponding to the highest element fluorescence. Scale bar: $500 \mu \mathrm{m}$. 


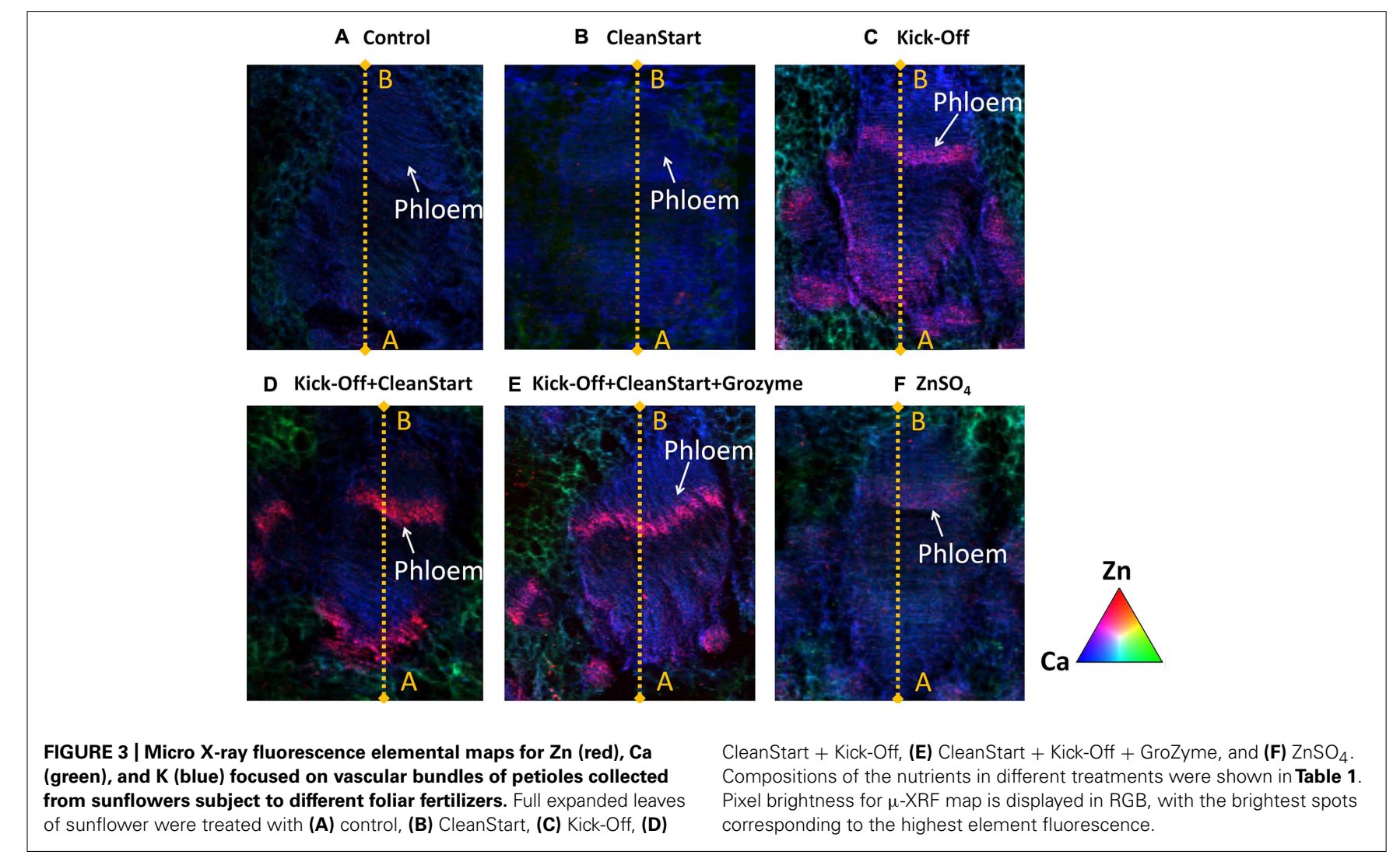

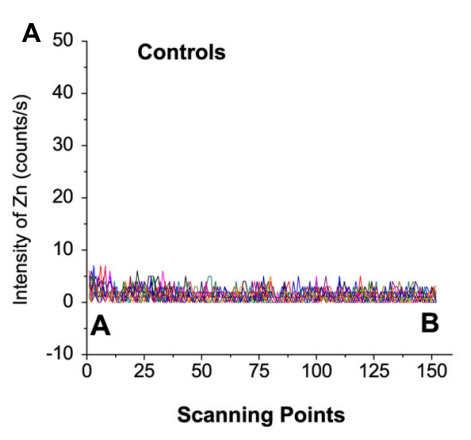

D

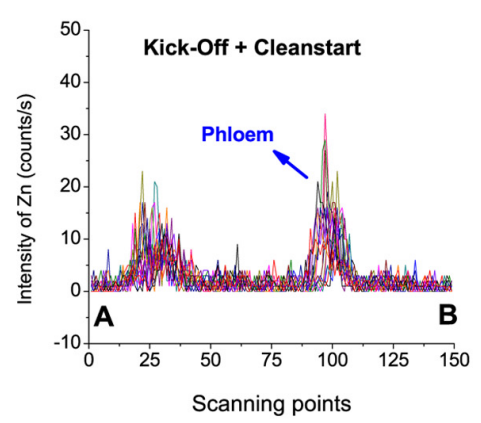

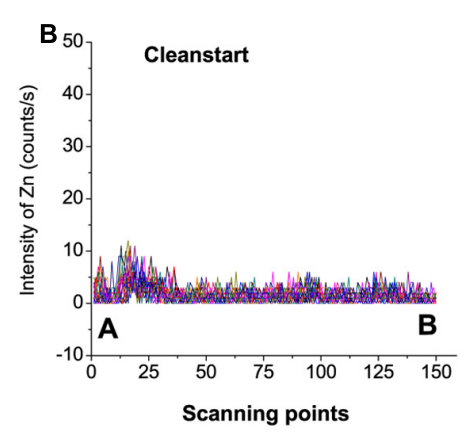

E

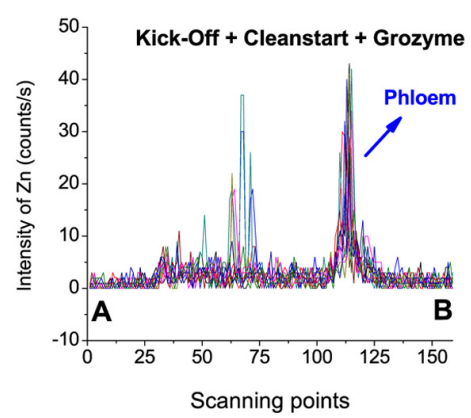

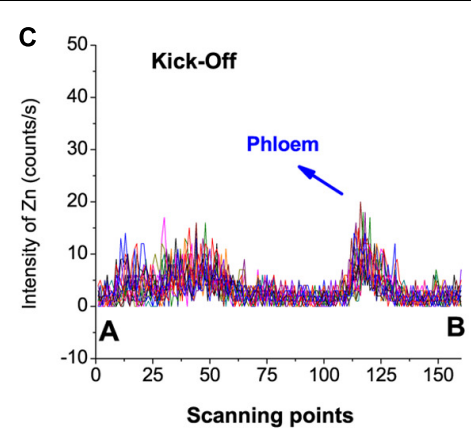

F

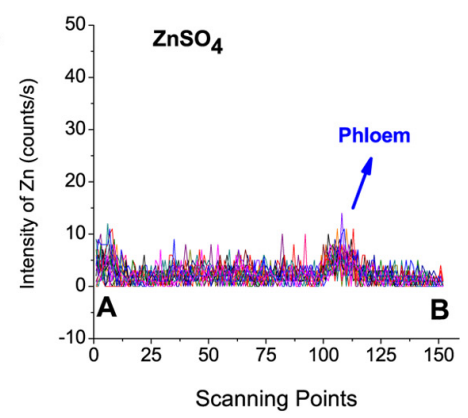

FIGURE 4 | Zinc intensities (counts/s) of 30-40 scan lines through the vascular bundles of petioles collected from sunflower plants treated with different foliar fertilizers. The selected scanning sites from point A to B are marked by yellow lines in Figure 3, with 30-40 scanning different lines selected for each plant sample. 
the vascular bundle with xylem on the adaxial or upper side of the petiole. The entire vascular bundle is enclosed in tissue that is likely collenchyma.

Integrated intensity for $\mathrm{Zn}$ and other elements were calculated from the spectrum and normalized by the intensity of the Compton scattering peak. Elemental mapping for the measurement area was obtained from the normalized intensity for each element. The elemental distribution maps of $\mathrm{Zn}$ (red), Ca (blue), and $\mathrm{K}$ (green) in the petioles collected from sunflowers plants with different treatments are presented in Figures 2A-F, together with corresponding photographs taken using an optical microscope (Figures 2a-f). The quantification of the fluorescence yields was normalized by $\mathrm{I}_{0}$ and the dwell time. The normalized X-ray fluorescence intensities were scaled to different color brightness for individual elements, with the brightest spots corresponding to the highest elemental fluorescence. Each map indicates the relative distribution of the three elements, and the scale of fluorescence counts for individual elements is the same for each map.

Very slight signals of $\mathrm{Zn}$ (red color) was noted in the petioles collected from the control and CleanStart treated plants of sunflower. The greatest concentration of $\mathrm{Zn}$ evident in the collenchyma immediately adjacent to the xylem (Figures 2a,b,A,B). At the resolution used in these experiments it is not possible to determine if the deposition of $\mathrm{Zn}$ in regions other than the phloem was resent in xylem or in collenchyma immediately adjacent to the xylem (referred to here as xylem/collenchyma). A modest increase in the $\mathrm{K}$ signal in petioles was also observed in the CleanStart treatment. Foliar application of "Kick-Off," a product containing $\mathrm{Co}, \mathrm{S}, \mathrm{Fe}, \mathrm{Cu}, \mathrm{Mn}, \mathrm{Mo}$, and Zn chelated with EDTA (Table 1) to sunflower leaves resulted in a marked increase in the concentration of $\mathrm{Zn}$ detected in the petioles with a notable deposition in a narrow band corresponding to the phloem tissues of the petiole and a more diffuse band in the xylem/collenchyma region (Figures 2c,C), while no such preferential localization to phloem tissues was noted for control, CleanStart or $\mathrm{ZnSO}_{4}$ treatments and no phloem specific accumulation of other elements was observed (data not shown). Application of $\mathrm{ZnSO}_{4}$ at the same $\mathrm{Zn}$ levels (200 $\left.\mathrm{mg} \mathrm{L}^{-1}\right)$ as used for all $\mathrm{Zn}$ treatments to the sunflower leaves also increased phloem $\mathrm{Zn}$ in the petioles (Figure $2 \mathbf{F}$ ) as compared with the controls (Figure 2A), but the effect is much less pronounced than that of "Kick-Off." The combined foliar application of "Kick-Off” with "CleanStart" resulted in a similar enhancement in $\mathrm{Zn}$ uptake and preferential distribution of $\mathrm{Zn}$ to phloem tissues and xylem/collenchyma. The addition of the biostimulant product GroZyme resulted in a much more concentrated enrichment of $\mathrm{Zn}$ in the phloem and xylem/collenchyma region of the petiole vascular bundle.

Low spatial resolution $\mu$-XRF imaging provides only semiquantitative data. To further investigate the effects of "CleanStart" and "GroZyme" on phloem mobility of foliar applied $\mathrm{Zn}$, microXRF scanning at higher resolution was performed, focusing on the vascular tissues of the treated leaf veins (Figure 3 ). The $\mathrm{Zn}$ concentration in the petiole was also determined along a single scan line that transected the petiole and passed through the vascular system. Both "CleanStart" and "GroZyme," which do not contain $\mathrm{Zn}$, clearly increased the

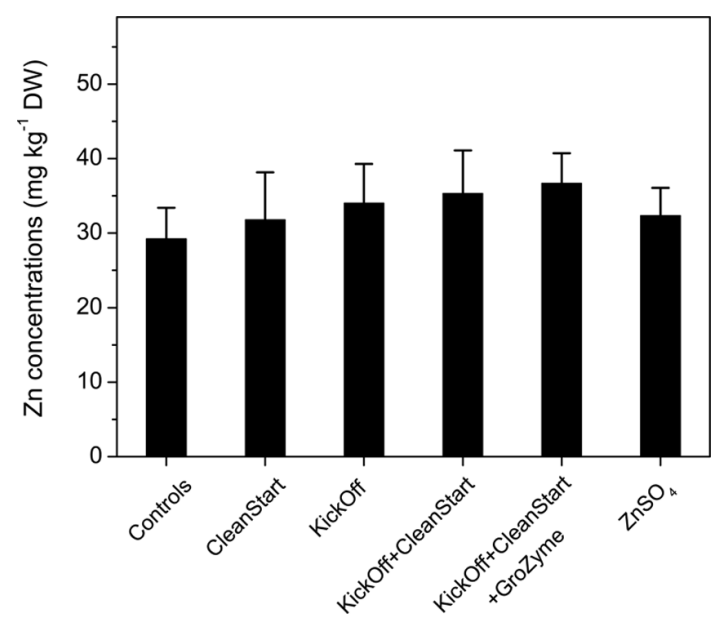

FIGURE 5 | Concentrations of $\mathrm{Zn}\left(\mathrm{mg} \mathrm{kg}^{-1} \mathrm{DW}\right)$ in the petioles collected from sunflower plants treated with different foliar fertilizers. Full expanded leaves of sunflower were treated with control, CleanStart, Kick-Off, CleanStart + Kick-Off, CleanStart + Kick-Off + GroZyme, and $\mathrm{ZnSO}_{4}$, and the $\mathrm{Zn}$ concentration of leaf veins were analyzed by ICP-MS. Compositions of the nutrients in different treatments were shown in Table 1. Data points and error bars represent means and SEs of three replicates $(n=3)$.

concentration of $\mathrm{Zn}$ following Kick-Off application. The patterns of $\mathrm{Zn}$ deposition in the "Kick-Off" + "CleanStart" and "KickOff" + "CleanStart" + "GroZyme" were far less diffuse and more intensely located in the phloem region and xylem/collenchyma than the pattern of $\mathrm{Zn}$ in petioles from leaves provided with "Kick-Off" or $\mathrm{ZnSO}_{4}$ alone. Intensity analysis (Figure 4) across a single scan line through the vascular system of the petiole demonstrated that the peak of $\mathrm{Zn}$ densities in the phloem tissues and xylem/collenchyma was markedly increased with addition of the biostimulant "GroZyme" to "Kick-Off" + "CleanStart" treatments (Figure 4E).

\section{TOTAL CONCENTRATIONS OF Zn IN LEAF VEINS}

Total concentrations of $\mathrm{Zn}$ and other elements including $\mathrm{Fe}, \mathrm{K}$, $\mathrm{Cu}, \mathrm{Ca}$, and $\mathrm{Mn}$ etc. were determined by ICP-MS for the petioles collected from the sunflowers treated with different foliar fertilizers. The results showed that $\mathrm{Zn}$ concentrations in the leaf veins of sunflower ranged from 29.2 to $36.7 \mathrm{mg} \mathrm{kg}^{-1} \mathrm{DW}$. While the overall pattern of $\mathrm{Zn}$ concentration differences analyzed by ICPMS corresponded with the $\mu$-XRF analysis results the total $\mathrm{Zn}$ concentration was not significantly different between treatments (Figure 5). Similarly, no difference in $\mathrm{Fe}, \mathrm{K}, \mathrm{Cu}, \mathrm{Ca}$, and Mn was observed among any treatments (Figure 6). The apparently greater sensitivity of $\mu$-XRF is primarily a consequence of the ability of $\mu$-XRF to analyze specifically within phloem and closely associated vascular organs while ICPMS provides analysis of the total petiole. Since vascular tissue represents only a very small proportion of the petiole as a whole, and as the petile was fully mature at the time of treatment, changes in vascular tissue element concentration may not be seen against the background of the bulk of petiole tissue in which $\mathrm{Zn}$ was not increased. 

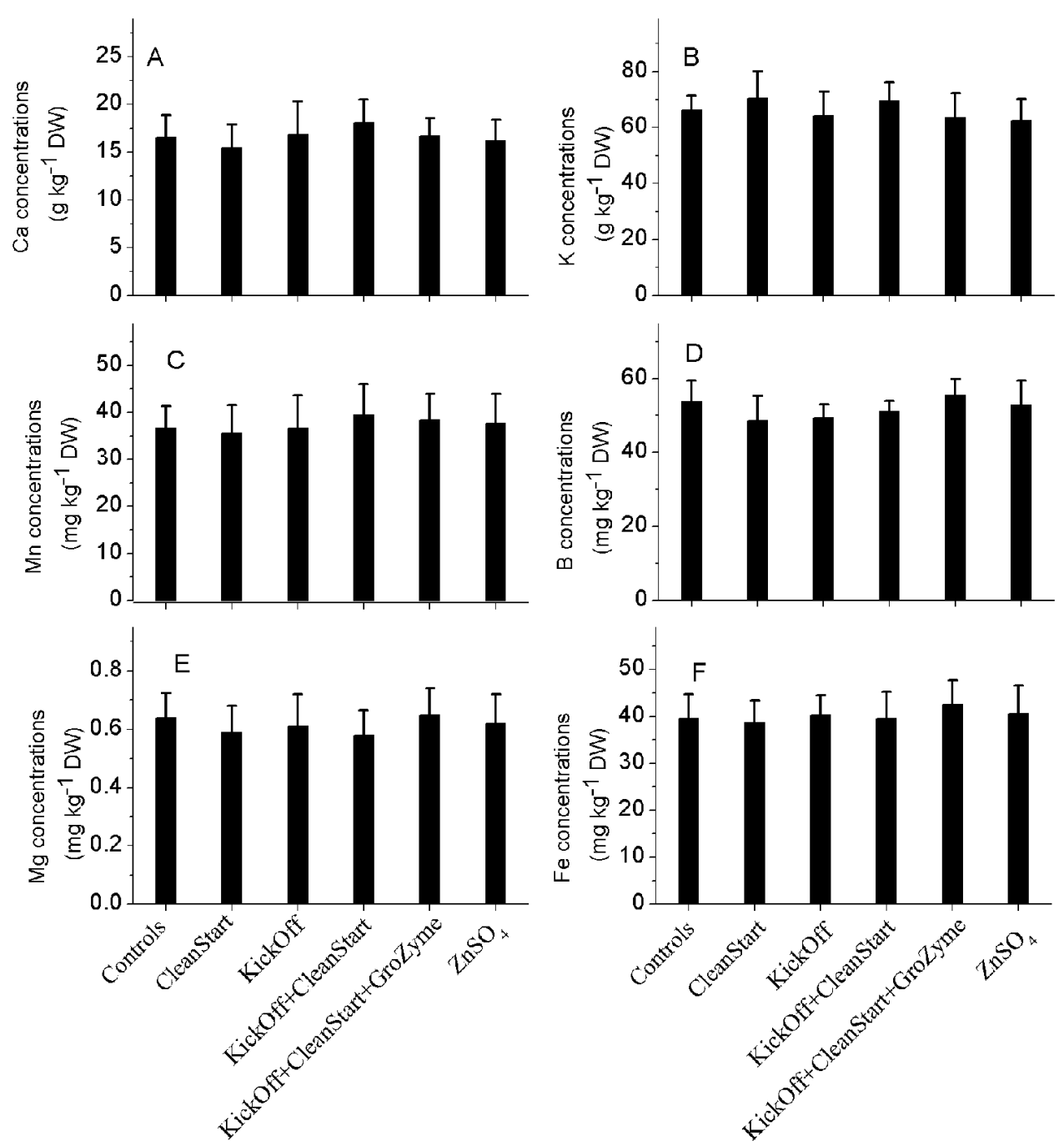

FIGURE 6 | Concentrations of $\mathrm{Mn}, \mathrm{Mg}, \mathrm{B}, \mathrm{Fe}\left(\mathrm{mg} \mathrm{kg}^{-1} \mathrm{DW}\right)$, and $\mathrm{Ca}, \mathrm{K}(\mathrm{g}$ $\mathbf{k g}^{-1} \mathrm{DW}$ ) in the petioles collected from sunflower plants treated with different foliar fertilizers. Full expanded leaves of sunflower were treated with control, CleanStart, Kick-Off, CleanStart + Kick-Off, CleanStart +
Kick-Off + GroZyme, and $\mathrm{ZnSO}_{4}$, and the concentrations of $\mathrm{Mn}, \mathrm{Mg}, \mathrm{B}, \mathrm{Fe}$, $\mathrm{Ca}, \mathrm{K}$ of leaf veins were analyzed by ICP-MS. Compositions of the nutrients in different treatments were shown in Table 1. Data points and error bars represent means and SEs of three replicates $(n=3)$.

\section{DISCUSSION}

Efficacy of foliar applied nutrients depends not only on the absorption of the nutrients but also on the transport of these nutrients to other plant parts (Bukovac and Wittwer, 1957; Fernández et al., 2013). It has been suggested that even a relatively small transport of foliar nutrients out of treated leaves and tissues may have a short-term, critical benefit to the plant (Fernández et al., 2013). Knowledge of the ability of an element to be transported from the site of application is critical to provide insight into the longevity and potential nutritional impact of foliar application on non-sprayed tissues.

Analysis by $\mu$-XRF in the present study shows clearly enhanced transport and localization of $\mathrm{Zn}$ in the vascular system of the sunflower petiole 7 days after application of "Kick-Off," which contains Zn-EDTA (Figure 2C), while Zn was not detectable in the petiole of the control plants (Figure 2A) and was very low in the petiole of $\mathrm{ZnSO}_{4}$ sprayed leaves (Figure 2F). This demonstrates clearly that $\mathrm{Zn}$ is phloem mobile in sunflower and that the use of $\mathrm{Zn}$-EDTA results in greater phloem $\mathrm{Zn}$ transport than $\mathrm{ZnSO}_{4}$ alone. While it has been demonstrated that Zn-EDTA is superior to $\mathrm{ZnSO}_{4}$ under some circumstances, it has not been demonstrated that the EDTA molecule can penetrate the leaf cuticle. It cannot be determined from this current research if the superiority of the EDTA containing Kick-Off material is a consequence of enhanced cuticular penetration or enhanced transport of the $\mathrm{Zn}$ once it enters the leaf. The 'Kick-Off' material also contains the microelements including $\mathrm{Fe}, \mathrm{Cu}, \mathrm{Mn}$, and $\mathrm{Mo}$ and this may also enhance $\mathrm{Zn}$ uptake as has been observed previously (Pipiska et al., 2008).

The addition of "CleanStart" derived from ammonia, urea, orthophosphoric acid and potassium hydroxide, significantly increased the phloem transport and xylem/collenchyma 
deposition of Zn when co-applied with 'Kick-Off' (Figures 3D and $4 \mathrm{D}$ ). Addition of Urea to foliar $\mathrm{Zn}$ sprays, for example, is known to enhance Zn uptake and efficacy (Stover et al., 1999; Johnson and Amdris, 2001; Sanchez et al., 2006) and the N status of cereals is known promote $\mathrm{Zn}$ retranslocation (Erenoglu et al., 2011; Barunawati et al., 2013; Xue et al., 2014). While it is clear that addition of the multi-elements present in the CleanStart enhanced $\mathrm{Zn}$ retranslocation into sunflower petioles, the mechanism of this effect remains uncertain.

The chemical form in which a foliar nutrient is applied will influence plant nutrient uptake by altering the point of deliquescence of the applied foliar fertilizer thereby altering its solubility on the leaf surface, or by altering the charge on the ion of interest to facilitate its movement through the cuticle and cell wall (Fernández et al., 2013). There is no direct evidence, however, to suggest that the formulation of a fertilizer spray can directly influence the transport of the absorbed nutrient from the site of application (Fernández and Brown, 2013).

The addition of the biostimulant "GroZyme" clearly enhanced $\mathrm{Zn}$ translocation when co-applied with "Kick-Off" and "CleanStart" (Figure 4E). Grozyme is a non-living microbial fermentation product derived from a proprietary mix of organic cereal grains inoculated with specific bacterial cultures and fermented. The specific functional metabolite in GroZyme has not been identified. However, extensive field trials and research published in this issue (Saa et al, this issue and unpublished research) have demonstrated positive growth effects and enhanced translocation of $\mathrm{K}$ and other nutrient elements (Saa et al, this issue and unpublished research). Previous research utilizing soil applications of GroZyme has also shown that this product was able to alter microbial populations in a soil environment and improve $\mathrm{N}$ mobilization and uptake of soil nutrients especially organic nitrogen (Chen et al., 2002, 2003). The benefit of bacterial source metabolites on efficacy of foliar fertilizers has been demonstrated previously (Ebrahim and Aly, 2004; Radzki etal., 2013) and it is plausible that the microbial extracts present in GroZyme have the capability to form metal complexes that enhance $\mathrm{Zn}$ uptake or mobility. Many putative biostimulants also contain plant growth hormones or plant signaling molecules that may alter plant metabolic processes and stimulate growth and indirectly influence the movement of substrates, including minerals, within the plant (Calvo et al., 2014).

In these experiment, the high spatial resolution and direct imaging capability of $\mu$-XRF was useful in distinguishing differences in $\mathrm{Zn}$ transport through the vascular system of sunflower that could not be detected by ICP-MS. XRF provides a powerful strategy to trace foliar applied microelements within the plants with high sensitivity, a result that is consistent with our previous studies (Lu et al., 2013b). This technique will be useful to facilitate the development of foliar fertilizers and application techniques that optimize transport of nutrients from site of application, which is one of the most important challenges to the foliar fertilizer industry.

\section{ACKNOWLEDGMENT}

This work was supported by projects from Ag spectrum, USA, the National Natural Science Foundation of China (31471939,
31370040), and China Geological Survey (12120113015400). Portions of this research were carried out at the Stanford Synchrotron Radiation Lightsource, SLAC National Accelerator Laboratory, is supported by the U.S. Department of Energy, Office of Science, Office of Basic Energy Sciences under Contract No. DE-AC0276SF00515. Authors sincerely thank John Labavitch, from University of California, Davis, and all staff of BL 2-3 at the Stanford Synchrotron Radiation Light source, particularly Courtney M. Roach, for their great support.

\section{REFERENCES}

Adamec, L. (2013). Foliar mineral nutrient uptake in carnivorous plants: what do we know and what should we know? Front. Plant Sci. 4:10. doi: 10.3389/fpls.2013.00010

Barunawati, N., Giehl, R. F. H., Bauer, B., and Von Wiren, N. (2013). The influence of inorganic nitrogen fertilizer forms on micronutrient retranslocation and accumulation in grains of winter wheat. Front. Plant Sci. 4:320. doi: 10.3389/fpls.2013.00320

Boaretto, A., Boaretto, R., Muraoka, T., Nascimento Filho, V., Tiritan, C., and Mourão Filho, F. (2001). Foliar micronutrient application effects on citrus fruit yield, soil and leaf $\mathrm{Zn}$ concentrations and $65 \mathrm{Zn}$ mobilization within the plant. Paper Presented at International Symposium on Foliar Nutrition of Perennial Fruit Plants, Meran.

Bukovac, M. J. (1985). Citation classic - absorption and mobility of foliar applied nutrients. Curr. Contents/Agric. Biol. Environ. Sci. 16.

Bukovac, M. J., and Wittwer, S. H. (1957). Absorption and mobility of foliar applied nutrients. Plant Physiol. 32, 428-435. doi: 10.1104/pp.32.5.428

Calvo, P., Nelson, L., and Kloepper, J. W. (2014). Agricultural uses of plant biostimulants. Plant Soil 383, 3-41. doi: 10.1007/s11104-014-2131-8

Chen, S. K., Edwards, C. A., and Subler, S. (2003). The influence of two agricultural biostimulants on nitrogen transformations, microbial activity, and plant growth in soil microcosms. Soil Biol. Biochem. 35, 9-19. doi: 10.1016/s00380717(02)00209-2

Chen, S. K., Subler, S., and Edwards, C. A. (2002). Effects of agricultural biostimulants on soil microbial activity and nitrogen dynamics. Appl. Soil Ecol. 19, 249-259. doi: 10.1016/s0929-1393(02)00002-1

Coelho Bezerra, F. T., Dutra, A. S., Ferreira Bezerra, M. A., De Oliveira Filho, A. F., and Barros, G. D. L. (2014). Vegetative behavior and productivity of the sunflower depending on the spatial arrangement of the plants. Rev. Cienc. Agron. 45, 335-343. doi: 10.1590/S1806-66902014000200015

Ebrahim, M. K. H., and Aly, M. M. (2004). Physiological response of wheat to foliar application of zinc and inoculation with some bacterial fertilizers. J. Plant Nutr. 27, 1859-1874. doi: 10.1081/lpla-200026442

Ebrahimian, E., Bybordi, A., and Eslam, B. P. (2010). Efficiency of zinc and iron application methods on sunflower. J. Food Agric. Environ. 8, 783-789.

Erenoglu, E. B., Kutman, U. B., Ceylan, Y., Yildiz, B., and Cakmak, I. (2011). Improved nitrogen nutrition enhances root uptake, root-to-shoot translocation and remobilization of zinc $(65 \mathrm{Zn})$ in wheat. New Phytol. 189, 438-448. doi: 10.1111/j.1469-8137.2010.03488.x

Fernández, V., and Brown, P. H. (2013). From plant surface to plant metabolism: the uncertain fate of foliar-applied nutrients. Front. Plant Sci. 4:289. doi: 10.3389/fpls.2013.00289

Fernández, V., Sotiropoulos, T., and Brown, P. H. (2013). Foliar Fertilization: Scientifc Principles and Field Practices, 1st Edn. Paris: IFA.

Jabeen, N., Ahmad, R., Sultana, R., Saleem, R., and Ambrat. (2013). Investigations on foliar spray of boron and manganese on oil content and concentrations of fatty acids in seeds of sunflower plant raised through saline water irrigation. J. Plant Nutr. 36, 1001-1011. doi: 10.1080/01904167.2013.766208

Johnson, R. S., and Amdris, H. L. (2001). Combining low biuret urea with foliar zinc sulfate sprays to fertilize peach and nectarine trees in the fall. Paper Presented at 4th International Symposium on Mineral Nutrition of Deciduous Fruit Crops, Penticton, BC.

Kannan, S. (2010). "Foliar fertilization for sustainable crop production," in Genetic Engineering, Biofertilisation, Soil Quality, and Organic Farming, ed E. Lichtfouse (Netherlands: Springer), 371-402. 
Lomascolo, A., Uzan-Boukhris, E., Sigoillot, J.-C., and Fine, F. (2012). Rapeseed and sunflower meal: a review on biotechnology status and challenges. Appl. Microbiol. Biotechnol. 95, 1105-1114. doi: 10.1007/s00253-012-4250-6

Lu, L., Tian, S., Liao, H., Zhang, J., Yang, X., Labavitch, J. M., et al. (2013a). Analysis of metal element distributions in rice (Oryza sativa L.) seeds and relocation during germination based on $\mathrm{x}$-ray fluorescence imaging of $\mathrm{Zn}, \mathrm{Fe}, \mathrm{K}, \mathrm{Ca}$, and Mn. PLoS ONE 8:e57360. doi: 10.1371/journal.pone.0057360

Lu, L., Tian, S., Zhang, J., Yang, X., Labavitch, J. M., Webb, S. M., et al. (2013b) Efficient xylem transport and phloem remobilization of $\mathrm{Zn}$ in the hyperaccumulator plant species Sedum alfredii. New Phytol. 198, 721-731. doi: 10.1111/nph. 12168

Mirzapour, M. H., and Khoshgoftar, A. H. (2006). Zinc application effects on yield and seed oil content of sunflower grown on a saline calcareous soil. J. Plant Nutr. 29, 1719-1727. doi: 10.1080/01904160600897430

Phattarakul, N., Rerkasem, B., Li, L., Wu, L., Zou, C., Ram, H., et al. (2012). Biofortification of rice grain with zinc through zinc fertilization in different countries. Plant Soil 361, 131-141. doi: 10.1007/s11104-012-1211-x

Pipiska, M., Hornik, M., Sekacova, J., Augustin, J., and Lesny, J. (2008). Influence of complexing ligands and mineral nutrients on zinc foliar uptake and transloction in vascular plants. Cereal Res. Commun. 36, 415-418.

Punshon, T., Guerinot, M. L., and Lanzirotti, A. (2009). Using synchrotron X-ray fluorescence microprobes in the study of metal homeostasis in plants. Ann. Bot. 103, 665-672. doi: 10.1093/aob/mcn264

Radzki, W., Gutierrez Manero, F. J., Algar, E., Lucas Garcia, J. A., Garcia-Villaraco, A., and Ramos Solano, B. (2013). Bacterial siderophores efficiently provide iron to iron-starved tomato plants in hydroponics culture. Antonie Van Leeuwen hoek Int. J. Gen. Mol. Microbiol. 104, 321-330. doi: 10.1007/s10482-0139954-9

Sah, R. N., and Brown, P. H. (1998). Isotope ratio determination in boron analysis. Biol. Trace Elem. Res. 66, 39-53. doi: 10.1007/bf02783124

Sanchez, E. E., Weinbaum, S. A., and Johnson, R. S. (2006). Comparative movement of labelled nitrogen and zinc in 1-year-old peach Prunus persica (L.) Batsch trees following late-season foliar application. J. Hortic. Sci. Biotechnol. 81, 839-844.

Skarpa, P. (2013). Effect of boron foliar application at critical growth stages on sunflower (Helianthus annuus L.) yield and quality. J. Elementol. 18, 449-459. doi: 10.5601/jelem.2013.18.3.09

Skarpa, P., Kunzova, E., and Zukalova, H. (2013). Foliar fertilization with molybdenum in sunflower (Helianthus annuus L.). Plant Soil Environ. 59, 156-161.

Stover, E., Fargione, M., Risio, R., Stiles, W., and Iungerman, K. (1999). Prebloom foliar boron, zinc, and urea applications enhance cropping of some 'Empire' and 'McIntosh' apple orchards in New York. HortScience 34, 210-214.

Tahir, M., Shah, S. A., Ayub, M., Tanveer, A., and Haseeb Ur, R. (2014). Growth and yield response of sunflower (Helianthus annuus L.) to sulphur and boron application. Pakistan J. Sci. Ind. Res. Ser. B Biol. Sci. 57, 5-10.
Tian, S. K., Lu, L. L., Labavitch, J. M., Webb, S. M., Yang, X. E., Brown, P. H., et al. (2014). Spatial imaging of $\mathrm{Zn}$ and other elements in Huanglongbing-affected grapefruit by synchrotron-based micro X-ray fluorescence investigation. J. Exp. Bot. 65, 953-964. doi: 10.1093/jxb/ert450

Tohidi-Moghadam, H. R. (2013). Comparative study on the effect of foliar application of micronutrients on growth, yield and seed oil content of sunflower (Helianthus annuus L.). Res. Crops 14, 833-838.

Webb, S. (2014). SMAK: Sam's Microprobe Analysis Kit, V1.1. Menlo Park, CA: Stanford Synchrotron Radiation Laboratory.

Wittwer, S. H., and Teubner, F. G. (1959). Foliar absorption of mineral nutrients. Ann. Rev. Plant Physiol. Plant Mol. Biol. 10, 13-32. doi: 10.1146/annurev.pp.10.060159.000305

Xue, Y.-F., Eagling, T., He, J., Zou, C.-Q., Mcgrath, S. P., Shewry, P. R., et al. (2014). Effects of nitrogen on the distribution and chemical speciation of iron and zinc in pearling fractions of wheat grain. J. Agric. Food Chem. 62, 4738-4746. doi: $10.1021 /$ jf500273x

Yang, H., Fan, Y., Duan, X., Wei, L., and Zhou, A. (2013). Boron effects on seed traits of sunflower by spraying on foliar. Chinese Agric. Sci. Bull. 29, 141-144.

Zhang, Q. L., and Brown, P. H. (1999). Distribution and transport of foliar applied zinc in pistachio. J. Am. Soc. Hortic. Sci. 124, 433-436.

Zhang, Y.-Q., Sun, Y.-X., Ye, Y.-L., Karim, M. R., Xue, Y.-F., Yan, P., et al. (2012). Zinc biofortification of wheat through fertilizer applications in different locations of China. Field Crops Res. 125, 1-7. doi: 10.1016/j.fcr.2011.08.003

Zhao, F.-J., Moore, K. L., Lombi, E., and Zhu, Y.-G. (2014). Imaging element distribution and speciation in plant cells. Trends Plant Sci. 19, 183-192. doi: 10.1016/j.tplants.2013.12.001

Conflict of Interest Statement: The authors declare that the research was conducted in the absence of any commercial or financial relationships that could be construed as a potential conflict of interest.

Received: 08 November 2014; paper pending published: 02 December 2014; accepted: 30 December 2014; published online: 21 January 2015.

Citation: Tian S, Lu L, Xie R, Zhang M, Jernstedt JA, Hou D, Ramsier C and Brown PH (2015) Supplemental macronutrients and microbial fermentation products improve the uptake and transport of foliar applied zinc in sunflower (Helianthus annuus L.) plants. Studies utilizing micro X-ray florescence. Front. Plant Sci. 5:808. doi: 10.3389/fpls.2014.00808

This article was submitted to Crop Science and Horticulture, a section of the journal Frontiers in Plant Science.

Copyright $\odot 2015$ Tian, Lu, Xie, Zhang, Jernstedt, Hou, Ramsier and Brown. This is an open-access article distributed under the terms of the Creative Commons Attribution License (CC BY). The use, distribution or reproduction in other forums is permitted, provided the original author(s) or licensor are credited and that the original publication in this journal is cited, in accordance with accepted academic practice. No use, distribution or reproduction is permitted which does not comply with these terms. 